\title{
Municipal solid waste pre-treatment: a comparison between two dewatering options
}

\author{
M. Ragazzi ${ }^{1}$, E. C. Rada $^{1,2}$, V. Panaitescu ${ }^{2}$ \& T. Apostol ${ }^{2}$ \\ ${ }^{1}$ Department of Civil and Environmental, Trento University, Italy \\ ${ }^{2}$ Polytechnic University of Bucharest, Romania
}

\begin{abstract}
In the field of Municipal Solid Waste (MSW) management, dewatering before combustion is adopted in particular cases. The aim is the modification of the waste characteristics in order to increase its LHV and allow an easier removal of glass, metals and other inert material. The process is named bio-drying when it is based on biological aerobic reactions; no auxiliary fuel is needed thanks to the exothermic reactions that develop under aerobic conditions. About 2.5 million $\mathrm{t}_{\mathrm{MSW}} / \mathrm{y}$ will be bio-dried in 2006 when all the bio-drying plants under construction will be completed. When the process is based on an external supply of heat (generally obtained from auxiliary fuel), the option is named thermal drying. This is well developed for sewage sludge but less for MSW. In Italy we can find a few experiences of thermal drying on the oversieve from MSW automatic sorting. In this case the aim is the decrease of humidity for the production of Refuse Derived Fuel (RDF) as, according to the Italian regulation, the highest value of humidity for RDF is $25 \%$. A few proposals of thermal drying have been proposed as a pre-treatment before combustion in two Italian towns where an incinerator has been planned. In both cases the proposal is integrated with the combustor (in order to use a part of the heat of the off-gases) and the aim is the preparation of the waste to an easier inert, glass and metals removal (for material recycling and for decreasing the impact of the incineration). The present paper shows a comparison between bio-drying and thermal drying taking into account MSW characteristics, environmental aspects, energy balances and costs. An additional comparison concerns the role of selective collection of biodegradable fraction in order to decrease the humidity of the residual MSW.
\end{abstract}

Keywords: bio-drying, dewatering, MSW, thermal drying. 


\section{Introduction}

In general, Municipal Solid Waste (MSW) dewatering before combustion is implemented in few cases. In the present paper, the characteristics of two options of MSW dewatering are put in comparison. The aim of MSW drying is the modification of the waste characteristics in order to increase its Lower Heating Value (LHV) and allow an easier removal of glass, metals and other inert materials. Indeed their automatic selection can be performed with higher efficiency as the lower amount of water decreases the interference of the organic fraction. The process is named bio-drying when it is based on exothermic biochemical reactions; the energy consumption is related to little consumption of the putrescible volatile solids and to the electricity needed to aerate the waste. The dewatering option is named thermal drying when an external auxiliary energy source allows the heating of the waste. This approach has been fully developed for sewage sludge but the applications on MSW are few. The present paper shows a comparison between bio-drying and thermal drying taking into account existing plants, MSW characteristics (mainly humidity), environmental aspects (air treatment needs), energy balances and costs. The selective collection of the biodegradable fraction can significantly decrease the humidity of the residual MSW and than must be taken into account when a dewatering option is analysed in a case-study.

\section{State of the art}

\subsection{MSW bio-drying}

The bio-drying sector is characterized by the presence of two main patents, thus general data are difficult to be found in the literature. The existing and planned plants in Europe are reported in Table 1. The main characteristics of those plants are shown as follows:

- Process duration: up to two weeks (depending on the patent, waste humidity and putrescibility).

- Waste height: lower than $6 \mathrm{~m}$ (the advantage of high values is related to the saving of surface, but a compression of the waste must be avoided in order to guarantee an adequate porosity).

- Waste density: $0.2-0.3 \mathrm{t} / \mathrm{m}^{3}$ (this values can change but strongly depends on the need of space for aeration).

- Air flow: $5-10 \mathrm{~m}^{3} / \mathrm{kg}_{\mathrm{MSw}}$ (depending on the patent, waste humidity and putrescibility).

- Air temperature: $40^{\circ} \mathrm{C}$ at the outlet of the biological reactor (it depends also on the air flow-rate).

- Weight loss: higher than $25 \%$ if humidity of waste is higher than $40 \%$ (this data cannot be generalized, as the efficiency of the process depends on the putrescibility of the waste). 
Table 1: $\quad$ Existing and planned bio-drying plants in Europe.

\begin{tabular}{|l|c|l|c|c|}
\hline \multicolumn{1}{|c|}{ Site } & Country & Starting & Capacity & Feeding \\
\hline Corteolona & Italy & 1996 & $100,000 \mathrm{t} / \mathrm{y}$ & Plug flow \\
\hline Giussago & Italy & 1996 & $40,000 \mathrm{t} / \mathrm{y}$ & Plug flow \\
\hline Asslar & Germany & 1997 & $140,000 \mathrm{t} / \mathrm{y}$ & Batch \\
\hline Bergamo & Italy & 1998 & $60,000 \mathrm{t} / \mathrm{y}$ & Plug flow \\
\hline Rennerod & Germany & 2000 & $100,000 \mathrm{t} / \mathrm{y}$ & Batch \\
\hline Montanaso & Italy & 2000 & $60,000 \mathrm{t} / \mathrm{y}$ & Plug flow \\
\hline Dresden & Germany & 2001 & $85,000 \mathrm{t} / \mathrm{y}$ & Batch \\
\hline Venise & Italy & 2001 & $125,000 \mathrm{t} / \mathrm{y}$ & Batch \\
\hline Lacchiarella & Italy & 2002 & $100,000 \mathrm{t} / \mathrm{y}$ & Plug flow \\
\hline Cavaglia & Italy & 2003 & $124,600 \mathrm{t} / \mathrm{y}$ & Plug flow \\
\hline Trier & Germany & 2004 & $180,000 \mathrm{t} / \mathrm{y}$ & Batch \\
\hline Grate Geel & Germany & 2004 & $150,000 \mathrm{t} / \mathrm{y}$ & Batch \\
\hline Osnabrück & Germany & 2004 & $85,000 \mathrm{t} / \mathrm{y}$ & Batch \\
\hline Villafalleto & Italy & 2004 & $60,000 \mathrm{t} / \mathrm{y}$ & Plug flow \\
\hline Berlin Région & Germany & 2005 & $135,000 \mathrm{t} / \mathrm{y}$ & Batch \\
\hline Dresden Région & Germany & 2005 & $120,000 \mathrm{t} / \mathrm{y}$ & Batch \\
\hline Nordhessen & Germany & 2005 & $180,000 \mathrm{t} / \mathrm{y}$ & Batch \\
\hline Dumfries & UK & 2005 & $65,000 \mathrm{t} / \mathrm{y}$ & Plug flow \\
\hline Castellan & Spain & 2006 & $103,000 \mathrm{t} / \mathrm{y}$ & Plug flow \\
\hline London & UK & 2006 & $360,000 \mathrm{t} / \mathrm{y}$ & Plug flow \\
\hline
\end{tabular}

\subsection{MSW thermal drying}

An international state of the art on MSW thermal drying does not exist. Anyway, a few interesting considerations can be made based on the Italian experiences in this sector.

In Italy we can find a few experiences of thermal drying on the oversieve from MSW automatic sorting. In this case the aim is the decrease of humidity for the production of Refuse Derived Fuel (RDF) as, according to the Italian regulation, the highest value of humidity for RDF is $25 \%$. The MSW screening allows a preliminary decrease of the humidity of the waste to be converted into $\mathrm{RDF}$, as most of the water content can be found in the undersieve that is not used for energy recovery (it is converted in stabilised organic fraction). Thus, when operating on an oversieve, the dewatering process can be considered a refinement of pre-treated waste and the auxiliary fuel necessary for its operation cannot be significant. After dewatering and inert, glass and metals separation, the obtained RDF can be used as a partial substitute of coal in cement factories. This option has been adopted for the first time in Italy in the province of Cuneo. Other countries, in particular Germany, seem to have longer experience about use of $\mathrm{RDF}$ in industrial plants.

Another experience concerned the use of a full stream thermal drying for the production of briquette-like RDF, in order to store the treated MSW during the years necessary for the implementation of a new incinerator. This is the case of a 
plant in the province of Milan, where a density of $1.2 \mathrm{t} / \mathrm{m}^{3}$ was obtained after shredding, thermal drying, sorting and extrusion of MSW. Today the waited incinerator is operating, so the thermal drying plant has been deactivated and a direct combustion of the residual MSW is implemented.

Recently, two proposals of thermal drying have been proposed as a pretreatment before combustion in two Italian provinces (Trento and Torino) where an incinerator has been planned. In both cases the thermal drying plant has been thought to be integrated with the combustor (in order to use a part of the heat of the off-gases, avoiding the cost of the auxiliary fuel) and the aim is the preparation of the waste to an easier inert removal; for material recycling and for decreasing the impact of the incineration (the effects on that are anyway limited). After a technical debate, only one of the two proposals has survived: the Trento one. On the contrary, in the province of Torino a partial decentralised pretreatment of bio-drying has been preferred.

\section{Comparison}

\subsection{Process comparison}

In Table 2, a preliminary comparison between bio-drying, thermal drying and bio-stabilisation (in order to understand its differences between the two biological processes) are presented.

Table 2: $\quad$ Main process parameters.

\begin{tabular}{|c|c|c|c|c|}
\hline $\begin{array}{c}\text { Parameters of } \\
\text { process }\end{array}$ & Bio-stabilization & Bio-drying & \multicolumn{2}{|c|}{$\begin{array}{c}\text { Thermal Drying } \\
\text { Waste }\end{array}$} \\
\hline $\begin{array}{c}\text { highest } \\
\text { temperature }\left({ }^{\circ} \mathrm{C}\right)\end{array}$ & 70 & 70 & 105 & 250 \\
\hline $\begin{array}{c}\text { min. temp. }\left({ }^{\circ} \mathrm{C}\right) \\
\text { For 3 days at least }\end{array}$ & 55 & 55 & 55 & 55 \\
\hline humidity & $\begin{array}{c}50 \% \\
\text { not limiting) }\end{array}$ & limiting & $\begin{array}{c}\text { not } \\
\text { limiting }\end{array}$ & $\begin{array}{c}\text { not } \\
\text { limiting }\end{array}$ \\
\hline $\begin{array}{c}\text { water } \\
\text { addition }\end{array}$ & yes & never & never & never \\
\hline $\begin{array}{c}\text { Oxygen limitation } \\
(\% \mathrm{v} / \mathrm{v})\end{array}$ & if $<10 \%$ & if $<10 \%$ & never & never \\
\hline
\end{tabular}

In case of bio-stabilization (before landfilling) the main difference with biodrying concerns the water addition, that is performed in order to optimize the biological process, as the energy balance is not important. This addition avoids developing the process under water limited conditions and gives a higher final consumption of volatile solids as shown in Figure 1. Both the biological processes develop well at temperature below $70^{\circ} \mathrm{C}$, to avoid sterilization effects that could inhibit the micro-organisms. 


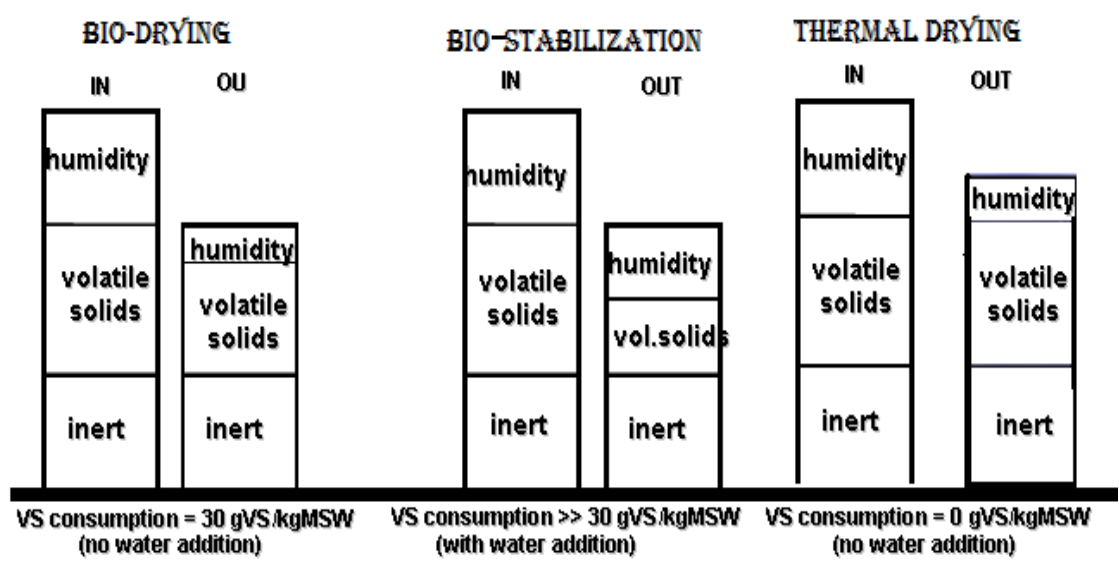

Figure 1: Volatile solids, non volatile solids and inert balances.

The aeration must guarantee an adequate oxygen availability; anyway the necessity of keeping the temperature under control causes air-flow that are not oxygen limiting. Temperature in case of MSW thermal drying is higher but cannot reach the values that characterize sewage sludge thermal drying. The reasons are two: a) there is a risk of ignition as the initial water contents are very different (for instance, $80 \%$ of humidity for sewage sludge, $25 \%$ of humidity for residual MSW); b) above $105^{\circ} \mathrm{C}$ there is a risk of softening of the plastics, with a consequent impossibility of managing the process.

Concerning the energy balances, bio-drying causes an internal consumption of about $3 \%$ of the initial LHV (Rada [1]). On the contrary, thermal drying has zero internal consumption but needs a significant amount of auxiliary fuel.

Concerning electricity consumption, bio-drying needs about $35-50 \mathrm{kWh} / \mathrm{t}_{\mathrm{MSW}}$ (Rada [1]); the electrical consumption of thermal drying is higher because of the higher air flow-rates to be supplied in a shorter period. These characteristics have some consequences on the costs of treatment: the operating costs for thermal drying are higher than the one of bio-drying. On the contrary, the quickness of the thermal drying allows the construction of a more compact plant, decreasing the capital costs.

The environmental impact of the two processes is different: bio-drying is a biological process, thus its emissions are related both to volatilization/extraction of pollutants already existing in the MSW (dioxin (Rada et al [2]), dust, etc.) and to generation of pollutants (ammonia, TOC, etc. (Rada et al [3])). In the case of thermal drying, there is only volatilization/extraction of pollutants already existing.

\subsection{Advantages comparison}

Bio-drying shows the following advantages:

- Several operating plants in real scale demonstrate that the technology is reliable. 
- No auxiliary fuel is needed for drying thanks to the biochemical oxidation of a small part of volatile solids; that makes it an interesting decentralized pre-treatment of MSW.

- The volume of the reactor is potentially available for temporary waste storing.

- A reduction of mass to be transported in case of decentralized treatment plants can decrease the number of tracks on the territory.

- The treated waste is suitable for inert, metals and glass separation at high efficiency as demonstrated in real scale plants.

- The increase of Lower Heating Value of the treated waste is interesting both for Refuse Derived Fuel production and for modifying the characteristics of waste, when not suitable for a direct combustion.

Thermal drying shows the following advantages:

- Easy regulation of the humidity (and therefore for the heating value) of the refuse exiting the plants, as there is no limitation from final humidity.

- Possibility of reaching humidity values lower than $10 \%$ for a good temporary material stability if the Waste to Energy plant is stopped for maintenance reasons.

- Short duration of the process (of the order of the hours or less) and rapidity of starting, as the process is not dependent on biological kinetics.

- Possibility of working with an elevated recycling of the process air (unlike a biological process, the oxygen content in the system is not a limiting factor; this option can keep the discharged air flow low, decreasing the costs for its treatment; a condensation stage must be implemented in order to allow the recycling of air).

- Independence from the selective collection strategies.

\subsection{Disadvantages comparison}

Bio-drying shows the following disadvantages:

- A fly's reproductive cycle must be taken into account; a specified removal stage (scrubber-like) must be implemented, but the obtainable efficiency is not $100 \%$.

- The long duration of the process (at least 1-2 weeks) causes the need of high reactor volumes.

- There is limited possibility of regulation of the humidity and of the LHV of the treated waste.

- A final humidity lower than $10 \%$ is not obtainable as low values are limiting the biological process.

- Elevated recycling of the process air is not viable because of the role of oxygen.

- The process air flow-rate to be treated is significant (even higher than the one necessary for incinerating the same amount of MSW). 
- The consumed volatile solids are no longer available for energy generation.

- Selective collection of organic fraction can significantly decrease its content in the residual MSW; as a consequence the biological process can be inhibited.

Thermal drying shows the following disadvantages:

- The necessity of auxiliary fuel makes thermal drying not viable for decentralized treatment (a centralized pre-treatment can exploit the heat generated from the centralized combustion of MSW).

- The necessity to maintain a low temperature of the process air $\left(<105^{\circ} \mathrm{C}\right)$ to avoid risks of softening of the plastics and phenomena of ignition of the material causes a high air flow in order to guarantee the heat necessary to remove water; high air flows mean high energy costs for the operation of the blowers.

- The thermal energy consumption for unit of mass of evaporated water is higher than the one for sewage sludge thermal drying, as the granulometry of MSW is less favorable and the technology is less optimized.

- No volume of storage for pre-treated waste is available because of the low retention time in the dryer.

\section{Conclusions}

In the present paper an overall comparison between two MSW dewatering options has been presented. MSW thermal drying is less developed than biodrying. The advantages and disadvantages pointed out demonstrate that the preference for the one or the other can be assessed case by case. Finally, a recommendation must be taken into account: MSW pre-treatment costs, thus if implemented, the chosen strategy will have clear advantages to it.

\section{References}

[1] Rada E. C. Municipal Solid Waste bio-drying before energy generation, PhD Thesis, University of Trento \& Politehnica University of Bucharest, 2005.

[2] Rada E.C., Ragazzi M., Panaitescu V., Apostol T. The role of biomechanical treatments of waste in the dioxin emission inventories. International Journal: Chemosphere, Vol 62/3, pp 404 - 410, 2006.

[3] Rada E. C., Ragazzi M., Panaitescu V., Apostol T. Some research perspective on emissions from bio-mechanical treatments of municipal solid waste in Europe. International Journal: Environmental Technology, Vol. 26, Nr.11, pp. 1297-1302(6), November 2005. 